\title{
Fine-scale genetic structure of natural Tuber aestivum sites in southern Germany
}

\author{
Virginie Molinier $^{1}$ - Claude Murat ${ }^{2} \cdot$ Andri Baltensweiler $^{1}$ - Ulf Büntgen ${ }^{1,3,4}$. \\ Francis Martin $^{2}$ • Barbara Meier ${ }^{1}$ - Barbara Moser ${ }^{1} \cdot$ Ludger Sproll $^{5}$ • Ulrich Stobbe ${ }^{5}$. \\ Willy Tegel $^{6} \cdot$ Simon Egli ${ }^{1} \cdot$ Martina Peter $^{1}$
}

Received: 9 March 2016 / Accepted: 28 June 2016 / Published online: 26 July 2016

(C) Springer-Verlag Berlin Heidelberg 2016

\begin{abstract}
Although the Burgundy truffle (Tuber aestivum) is an ectomycorrhizal fungus of important economic value, its subterranean life cycle and population biology are still poorly understood. Here, we determine mating type and simple sequence repeat (SSR) maternal genotypes of mapped fruiting bodies to assess their genetic structure within two naturally colonized forest sites in southern Germany. Forty-one genotypes were identified from 112 fruiting bodies. According to their mating types, the maternal genotypes were aggregated only in one population. Genotypic diversity of individuals that mostly were small and occurred in 1 out of 2 years of sampling was high. Although these results suggested a ruderal colonization strategy, some genets spread several hundred meters. This result indicates that, besides sexual spore dispersal, vegetative growth or spreading by mycelial propagules contributes to dissemination. In one site, fewer individuals with a tendency to expand genets belonging to only one genetic
\end{abstract}

Electronic supplementary material The online version of this article (doi:10.1007/s00572-016-0719-y) contains supplementary material, which is available to authorized users.

Virginie Molinier

molinier.virginie@gmail.com

1 Swiss Federal Institute for Forest Snow and Landscape Research (WSL), Birmensdorf 8903, Switzerland

2 INRA, Université de Lorraine, UMR1136 Interactions Arbres-Microorganismes, Laboratoire d'Excellence ARBRE, F-54280 Champenoux, France

3 Oeschger Centre for Climate Change Research, Bern, Switzerland

4 Global Change Research Centre AS CR, Brno, Czech Republic

5 Deutsche Trüffelbäume, Radolfzell, Germany

6 Institute of Forest Sciences IWW, Freiburg University, Freiburg, Germany group were observed. In the second site, numerous small individuals were found and were grouped into two clearly differentiated genetic groups that were spatially intermingled. Forest characteristics and disturbances are possible reasons for the observed genetic patterns. Our findings contribute to a better understanding of the biology of one of the most widespread and commercially important truffle species. This knowledge is critical for establishing and maintaining sustainable long-term truffle cultivations.

Keywords Burgundy truffle $\cdot$ Genets $\cdot$ Mating-type genes · Population genetics $\cdot$ Propagation strategy $\cdot$ SSR markers

\section{Introduction}

True truffles are ectomycorrhizal fungi belonging to the genus Tuber in Ascomycetes. This genus, which exclusively forms hypogeous fruiting bodies, comprises more than 200 species all over the world (Bonito et al. 2013; Bonito et al. 2010), of which at least 30 naturally occur in Europe (Ceruti et al. 2003). Some of these species are well known for their organoleptic properties and their high economic value, such as Tuber magnatum (Alba white truffle), Tuber melanosporum (Périgord black truffle), and Tuber aestivum Vittad. (Burgundy and summer truffles, depending on the harvesting period). This last species is indigenous to many European countries and, unlike the other two species, has a widespread distribution range from Sweden to Spain (Stobbe et al 2013a). T. aestivum has also been found outside Europe in North Africa (Jeandroz et al. 2008). Since the 1970s, T. aestivum as well as some other truffle species have been successfully cultivated in truffle orchards (Chevalier et al. 1973). To date, most studies have focused on the species' taxonomic status (Mello et al. 2002; Molinier et al. 2013b; Paolocci et al. 2004; 
Weden et al. 2005), aroma profiles (Cullere et al. 2010; Diaz et al. 2009; Splivallo et al. 2012) and genetic diversity (Molinier et al. 2015b) including potential links to aroma (Splivallo et al., 2012; Molinier et al. 2015a). The cultivation potential and requirements of these species (Benucci et al. 2012; Shamekh et al. 2014; Stobbe et al. 2013a; Stobbe et al. 2013b), including soil conditions (Benucci et al. 2011; Gryndler et al. 2011; Salerni et al. 2014), have also been investigated previously. However, the small scale genetic structure and the distribution of the mating-type strains of T. aestivum remain largely unknown.

The genome sequencing of T. melanosporum in 2010 (Martin et al. 2010), as well as numerous other studies of T. melanosporum (Murat et al., 2013; Riccioni et al. 2008; Rubini et al. 2005, 2011a, b), T. magnatum (Paolocci et al. 2006; Riccioni et al. 2008; Rubini et al. 2005, 2011a, b) and T. indicum (Belfiori et al. 2013) have revealed that these species are heterothallic, as has lately been confirmed for T. aestivum (Payen et al. 2014). While homothallic species present both mating types (MAT) in a single genome, rendering them self-fertile, heterothallic species bear only one of the two idiomorphs in the MAT locus (Billiard et al. 2012). The same haploid mycelium can produce male (antheridia) and female (ascogonia) organs, although these structures have hardly been observed in Tuber species (Le Tacon et al. 2015). To achieve its life cycle, an ascogonium has to be fertilized by a strain of the opposite mating type. In truffles, a fruiting body is composed of peridium, gleba and ascospores. The gleba is a haploid tissue consisting of the maternal parent genotype, which is usually also found as mycelia in the surrounding soil and on nearby ECM root tips (Murat et al. 2013; Rubini et al. 2011a). In contrast, ascospores originate from the recombination of the maternal and paternal genotypes (Le Tacon et al. 2015).

Since Tuber spp. are hypogeous, their propagation mainly depends on insects and larger animals as spore vectors (Trappe and Claridge 2005). Hypogeous species are thought to have a shorter distance dispersion potential than epigeous species, which have air-dispersed spores, with related effects on the gene flow and genetic structure. The consequence of a short dispersal distance is greater population differentiation and isolation by distance at smaller spatial scales for hypogeous fungi such as Rhizopogon occidentalis, $R$. vulgaris and Tuber melanosporum (Murat et al. 2013; Grubisha et al. 2007). A fine-scale population structure analysis carried out in two T. melanosporum plantations using fruiting bodies and mycorrhizas demonstrated a profound isolation by distance in the first $5 \mathrm{~m}$ and found that belowground genets had a maximum size of a few meters (Murat et al. 2013). The observed patterns were assumed to be a combination of vegetative mycelial growth of a few genets that persisted for several years and an annual recruitment of new genets via the ascospores. Intriguingly, genotypes were not spatially randomly distributed in T. melanosporum plantations and natural fields but rather occurred in clusters according to their MAT idiomorph (Murat et al. 2013; Rubini et al. 2011a). Such a spatial segregation of mating types would decrease the probability that compatible cells meet, which could be beneficial under the assumption that sex is costly (Selosse et al. 2013). This segregation of the mating-type strains raises the question of where paternal individuals come from and what structures they might consist of (Le Tacon et al., 2015).

Sequencing of the T. aestivum genome is currently being completed (Payen et al., 2014), and the first sequences have facilitated the development of specific simple sequence repeat markers (SSR) (Molinier et al. 2013a). A first assessment of the species' genetic structure at the European-scale revealed the existence of well-differentiated sympatric genetic groups, indicating different ecotypes (defined as genetically distinct varieties within a species that are adapted to specific environmental conditions) with reduced gene flow, although this previous study provided no clues about how these ecotypes are spatially distributed (Molinier et al. 2015b). At much smaller scales, a recent study that focused on the link between genetic structure and aroma in an orchard naturally colonized by T. aestivum indicated that genet sizes (up to $92 \mathrm{~m}$ ) are larger than those of T. melanosporum (Molinier et al. 2015a; Murat et al. 2013). However, the limited sample size did not allow any deep genetic structure analyses, and the mating-type genotype distribution was not considered.

Here, we analysed the spatial and temporal genetic structure of two natural T. aestivum populations in southern Germany. Mating-type genes and SSR markers on maternal tissue from fruiting bodies were used to address (1) how the mating types are distributed, (2) how the genets are spatially structured on a small-scale, and (3) how the persistence of genotypes evolves over time. We compare our results with previous findings about the small-scale genetic structure of T. melanosporum and thereby provide new insight into the life cycle of $T$. aestivum.

\section{Materials and methods}

\section{Sites description and sampling of fruiting bodies}

T. aestivum fruiting bodies were collected in two forest sites (Ueberlingen (UL) and Bohlingen (BB)) located about $3 \mathrm{~km}$ apart from each other in southwest Germany near Lake Constance. Due to the risk of illegal truffle harvesting on these long-term monitoring sites, the exact locations are kept confidential but a schematic map is provided in Fig. S1.

Bohlingen is a single-storied, even aged ( $>100$ years) and conventionally managed beech forest with little understory vegetation, whereas UL is a multi-storied, uneven aged and poorly managed mixed beech-oak forest with abundant understory vegetation. On both sites, the tree layer is dominated by 
Fagus sylvatica, but the second-most dominant species is Quercus robur on UL and Acer campestris on BB. Further tree species are Carpinus betulus and Robinia pseudoacacia on UL, and Fraxinus excelsior on BB. UL was selected in 2011 due to the consistent presence of $T$. aestivum fruiting bodies over several years. This forest stand is spatially restricted to about $5000 \mathrm{~m}^{2}$ by surrounding agricultural fields and is located at least $250 \mathrm{~m}$ away from the neighbouring forests. In 2013, the BB experimental site was selected due to its high T. aestivum fruiting body productivity and is part of a forest with an area of approximately $40,000 \mathrm{~m}^{2}$.

To obtain more detailed information about the site characteristics (e.g. host- and non-host trees) and potential environmental differences between them, we performed a vegetation survey within a circular plot with an area of $200 \mathrm{~m}^{2}$ in each study site. In each of these plots, we assessed the composition and coverage of herbs, shrubs (woody plants with a height between $0.5 \mathrm{~m}$ and $5.0 \mathrm{~m}$ ) and tree species. From these data, the Shannon index and the Landolt indicator values were calculated. Indicator values refer to the ecology and biology of individual plant species and aim at characterising species' niches in natural plant communities (Landolt 2010). Average Landolt indicator values of a plant community mirror local site conditions, e.g. with respect to temperature, soil moisture or nutrients. Physico-chemical soil characteristics of each of the two truffle sites were studied by collecting 16 soil cores (0-15 cm in depth), which were pooled at the site level and then analysed by SADEF company (Aspach-France).

Fruiting body sampling was carried out in a 1-day harvest in October 2011 at site UL and in a 2-day harvest in October 2013 at both sites with four trained truffle dogs. All fruiting bodies were retrieved from the soil and precisely mapped using GPS technology. The fresh weight of each fruiting body was measured, and its maturity stage was determined according to a protocol based on Zeppa et al. (2004). Under a microscope ( $\times 400$ magnification), asci (sexual spore-bearing cells produced in ascomycete fungi) were counted and sorted into three different categories: (1) asci with mature spores (yellow-brown colour with a fully formed ornamentation), (2) immature asci with immature spores (white colour and without or incompletely formed ornamentation) and (3) empty asci or absence of asci. The degree of maturity of the fruiting bodies (percent mature) was calculated as follows: the number of mature asci (category 1) divided by the total number of asci (categories 1, 2 and 3). For each fruiting body, observation and calculation were performed five times, each with a different microscopic slide. Samples of fruiting bodies were kept at $-20{ }^{\circ} \mathrm{C}$ until further analyses.

\section{DNA extraction, mating-type genes and SSR amplifications}

Genomic DNA of the fruiting bodies was isolated from gleba of each sample using DNeasy® Plant Mini Kit (Qiagen,
Hilden, Germany) according to the manufacturer's instructions. Extracts were eluted in $50 \mu \mathrm{l}$ of Buffer AE supplied as part of the kit. To identify the mating type of each fruiting body, specific primer pairs were designed for each MAT idiomorph based on $T$. aestivum genome sequences (Accession numbers: LT593973 TuaestMAT1-1 gene (European Nucleotide Archive); JB402662.1 TuaestMAT1-2 gene (Genbank)); aest-MAT1-1f (5' CTACATTCTGGTGG GCGATT 3')/aest-MAT1-1r (5' TCCCGATTTGTCCA ACGTAT $\left.3^{\prime}\right)$ and aest-MAT1-2f (5' ATCGTCGGGACTCA TCTCAC 3')/aest-MAT1-2r (5' CGGATATTGGGATT TGATGG $3^{\prime}$ ). For mating-type gene amplification, multiplex PCRs were performed in a total volume of $25 \mu$ consisting of $2.5 \mu$ of $10 \times$ REDTaq PCR Buffer $\left(11 \mathrm{mM} \mathrm{MgCl}_{2}\right.$; Sigma: B5926), $5 \mu \mathrm{dNTP}$, (1 mM, Life Technologies), $1 \mu \mathrm{l}$ multiplex solution containing the four primers (10 $\mu \mathrm{M}$ each), $1.25 \mu \mathrm{l}$ RED Taq Polymerase, (1 U/ $\mu$ l, Sigma: D4309), $13.25 \mu \mathrm{l}$ of sterile water and $2 \mu \mathrm{l}$ template DNA diluted 10 times. The PCR reactions were performed in a Veriti ${ }^{\circledR}$ thermal cycler (Applied Biosystems, Foster City, CA, USA) with the following conditions: $2 \mathrm{~min}$ at $94{ }^{\circ} \mathrm{C}$ followed by 28 cycles of denaturation at $94^{\circ} \mathrm{C}$ for $30 \mathrm{~s}$, annealing at $57^{\circ} \mathrm{C}$ for $30 \mathrm{~s}$, extension at $72{ }^{\circ} \mathrm{C}$ for $1 \mathrm{~min}$, and a final extension at $72{ }^{\circ} \mathrm{C}$ for $7 \mathrm{~min}$. PCR products were run on $1.5 \%$ agarose gel and visualized with a UV transilluminator after ethidium bromide staining.

The extracted DNA from fruiting bodies was amplified using a set of 14 SSR loci (aest01, aest06, aest07, aest10, aest15, aest18, aest24, aest25, aest26, aest28, aest29, aest31, aest35 and aest36) developed previously by Molinier et al. (2013a). Polymerase chain reactions were carried out using the Qiagen Multiplex PCR kit (Qiagen, Germany) following the manufacturer's instructions. PCRs were performed in a total volume of $7 \mu \mathrm{l}$, consisting of $3.5 \mu \mathrm{l}$ of Qiagen Multiplex Buffer $(2 \times), 1.8 \mu$ l of sterile water, $0.7 \mu$ primer premix $(2 \mu \mathrm{M})$ and $1 \mu \mathrm{l}$ template DNA diluted 10 times. Two different primer premixes were used according to the expected allelic sizes to avoid overlapping. Both multiplex mixtures had the same PCR conditions: samples were denatured at $95^{\circ} \mathrm{C}$ for $15 \mathrm{~min}$, followed by 28 cycles consisting of a denaturing step at $94{ }^{\circ} \mathrm{C}$ for $30 \mathrm{~s}$, an annealing step at $60{ }^{\circ} \mathrm{C}$ for $1 \mathrm{~min}$ and an extension step at $72{ }^{\circ} \mathrm{C}$ for $1 \mathrm{~min}$. A final extension step at $60{ }^{\circ} \mathrm{C}$ for $30 \mathrm{~min}$ was added after 28 cycles. For the subsequent genotyping step on ABI-3130 (Applied Biosystems, USA), PCR products were diluted in pure water (1/4) and then mixed with HiDi Formamide. As an internal size standard, GeneScan ${ }^{\mathrm{TM}} 500$ LIZ $^{\mathrm{TM}}$ dye Size Standard (ThermoFisher Scientific, USA) was used.

\section{Data analyses}

To investigate the sexual behaviour of $T$. aestivum, we first used the mating-type genes alone. Genetic and clonal 
structures were investigated using 14 SSR markers combined with the mating-type gene.

\section{Identification of repeated multilocus genotypes}

A multilocus genotype (MLG) was assigned to each fruiting body. To distinguish true clones from samples carrying the same MLG by chance, the probability that copies of a MLG arose from sexual reproduction $\left(P_{\text {sex }}\right)$ was calculated using MLG $_{\text {SIM }}$ (Stenberg et al. 2003). $P_{\text {sex }}$ values were generated by 10,000 simulations using a Monte Carlo simulation method. A significant $P_{\text {sex }}$ value suggests that multiple copies of the same MLG arose from asexual reproduction and growth (true clones). In contrast, a non-significant $P_{\text {sex }}$ value suggests that the number of occurrences observed for a repeated MLG resulted from sexual reproduction (by chance). In the latter case, the occurrences were treated as different individuals. The number of MLGs and genotypic diversity, as well as versus the number of loci, were calculated for one member of each MLG using Multilocus 1.3 (Agapow and Burt 2001). Given the clonality observed, subsequent analyses were conducted on a global data set including all individuals (ramet level) and on a clone-corrected data set including one member of each MLG (simple clone-corrected dataset). For some spatial analyses (i.e. aggregation index, autocorrelation analyses), we assigned up to four centred location points per MLG for large MLGs $(>15 \mathrm{~m}$ ) in the clone-corrected data set (partial clone-corrected dataset) (Fig. S2).

\section{Mating-type distribution}

We tested whether the proportion of MAT1-1 and MAT1-2 isolates were equal within each population. For assessing the significance of deviation from a 1:1 mating-type ratio (null hypothesis) in a population, we used the exact binomial test at the ramet and genet levels. In a random distribution context, this ratio should be equal to one. On each site, we calculated the aggregation of mating types using Genclone software (Arnaud-Haond and Belkhir 2007) to study the potential clustering of the individuals harbouring the same mating type. For this analysis, two different levels were performed: at the ramet level and, also, we used the partial clone-corrected dataset with several centred location points for large MLGs. For each analysis, only the MAT gene information was used.

\section{Clonal diversity and fine-scale spatial genetic structure analyses}

Within each population (BB, UL 2011, UL 2013 and UL 2011/2013), according to Arnaud-Haond et al. (2007), we used Genclone software to calculate several indices thought to be the most parsimonious set of non-redundant indices of clonal diversity (Arnaud-Haond and Belkhir 2007) : (1) the genotypic diversity $(R=$ (number of $\mathrm{MLG}-1) /$ (number of ramets -1$)$ ), which ranges from 0 to 1 where 0 means the entire population is one clone (with the same genotype) and 1 means every sample (here fruiting bodies) is one unique clone (each sample possesses a different genotype); (2) the adapted Simpson index for genotypic diversity $\left(D^{*}\right)$, which ranges from 0 to 1 where 1 represents maximum diversity; (3) the corresponding evenness index (ED*), which ranges from 0 to 1 where 1 means that all MLG are equal in abundance; and (4) the complement of the slope of the Pareto distribution of clonal membership ( $c$ Pareto). The Pareto coefficient increases as the diversity and evenness in the sample increase.

In order to describe the spatial component of clonal growth and the intermingling of repeated MLGs, we used Genclone software (Arnaud-Haond and Belkhir 2007) to estimate the spatial aggregation index (Ac) and the edge effect (Ee), as described by Arnaud-Haond et al. (2007). The Ac index ranges from 0 , where the probability that nearest neighbours have the same MLG does not differ from the average probability across all occurrences, to 1 , where all nearest neighbours preferentially share the same MLG. The statistical significance of the aggregation index was tested against the null hypothesis of a spatially random distribution of isolates using a re-sampling approach based on 1000 permutations. The edge effect (Ee) estimates the effect of sampling on the estimates of genotypic diversity, especially potential overestimation due to the presence of large clones sampled only once or a few times at the edge of the sampling area. Finally, the clonal subrange (maximum distance between two samples with same MLG) was calculated and used to represent the size of the largest genet.

A spatial autocorrelation approach was used to investigate the spatial genetic structure within each truffle site. We used the kinship coefficient $\left(F_{\mathrm{ij}}\right)$ (Loiselle et al. 1995) as a means of measuring the relatedness between each pair of fruiting bodies. We defined 17 distance classes and tested whether the observed values of $F_{\mathrm{ij}}$ within each distance class differed significantly from 0 (random structure) by using 10,000 permutations of spatial locations in the program SPAGEDI 1.3 (Hardy and Vekemans 2002). Spatial genetic structure was quantified with the Sp statistic, estimated as $-b /\left(1-F_{1}\right)$, where $b$ is the slope of the regression of $F_{\mathrm{ij}}$ on the logarithm of the geographical distance separating the pairs of fruiting bodies, and $F_{1}$ is the mean kinship coefficient of the first distance class (Hardy 2003). We performed these analyses at the ramet level, which addresses clonal, vegetative growth, and with the partial clonecorrected dataset, which focuses on sexual spore dispersal.

\section{Population subdivision}

We investigated population subdivision using the entire dataset and the Bayesian method implemented in STRUCTURE 2.3.4 (Pritchard et al. 2000). STRUCTURE infers the best number of genetic groups $(K)$ or sub-populations. The admixture model 
with correlated allele frequencies was selected as an appropriate option for the analysis. The burn-in period and Markov Chain Monte Carlo value (MCMC) were set to 500,000 and 750,000 iterations, respectively, and 20 replicates per $K$ were run. As recommended, successive $K$ values (number of populations) from 1 to 10 were used to obtain the distinct genetic group and to estimate the number of subpopulations. The final posterior probability of $K, \operatorname{Ln} \mathrm{P}(K)$ and Delta $K(\Delta K)$, defined as the rate of change of $L n \mathrm{P}(K)$ between successive $K$ values (Evanno et al. 2005), was calculated using Structure Harvester (Earl and vonHoldt 2012) to determine the most likely number of genetic groups. Genetic group pairwise $F_{\text {st }}$ calculations, pairwise kinship coefficients $\left(F_{\mathrm{ij}}\right)$ and intra-genetic group kinship coefficients $\left(G_{\mathrm{ij}}\right)$ were calculated using SPAGeDi software (Hardy and Vekemans 2002). When subpopulations were observed, we calculated the average fruiting body maturity and weight, as well as the correlation between these two parameters within each genetic group (Pearson's correlation), and tested if genetic groups differ in these parameters (ANOVA by permutation). When subpopulations were observed within the site, we performed spatial aggregation analyses as described above.

\section{Control for sampling biases}

To infer a possible sampling bias due to differences in sampling area surface, clonal parameters were calculated for several sampling scenarios. In 2013, truffles were harvested from a larger area on site $\mathrm{BB}$ than on site UL, but the same sampling area $(80 \times 45 \mathrm{~m})$ was used for calculations for each site (Fig. S3, case 1). Because the sampling area on UL was smaller in 2011 than in 2013, the calculations were done with a subset of the samples collected in 2013 (Fig. S3, case 2). To investigate if the localization of the sampling area within an individual site plays a role in the genetic results, calculations were performed for three rectangular sampling areas. The rectangles, each with a size of $95 \times 35 \mathrm{~m}$, were placed randomly on BB (Fig. S3, case 3).

\section{Mapping}

To map mating types and MLG, and to calculate distance values for the genetic group analysis, we used the program ArcGIS 10.2 (ESRI, Redlands, CA, USA).

\section{Results}

\section{Truffles harvests}

Vegetation and soil characteristics for BB and UL are summarized in Table S1 and Fig. S4. In total, 112 truffle fruiting bodies were harvested. On BB, 42 fruiting bodies were collected within $9540 \mathrm{~m}^{2}$ in 2013. In UL, 31 fruiting bodies were collected in an area of approximately $1000 \mathrm{~m}^{2}$ in 2011, and 39 fruiting bodies within $2350 \mathrm{~m}^{2}$ in 2013 . No significant differences in maturity or weight were found between fruiting bodies collected in the two different sites. Details about weight, maturity and correlation calculations for each population are given in Table $\mathrm{S} 2$.

\section{Mating-type genes and their spatial distribution within the truffle sites}

For fruiting body gleba (i.e. maternal tissue), due to the haploid nature of this tissue (Paolocci et al., 2006), only one MAT locus was detected. When looking at all sampled fruiting bodies (ramet level), the ratio MAT1-1: MAT1-2 maternal tissue was 0.90 in $\mathrm{BB}$ and did not deviate significantly from a 1:1 mating-type ratio (not significant; Table 1). In UL, however, significantly more fruiting body maternal tissue presented the MAT11 locus, with MAT1-1: MAT1-2 ratios of 3.11 ( $p$ value $<0.01$, UL samples from 2011 and 2013 pooled (UL 2011/2013)), 2.1 (not significant, samples from 2011) and 4.57 ( $p$ value $<0.01$, samples from 2013; Table 1). When considering all fruiting bodies, the mating-type distribution visually seemed rather homogenous in the site $\mathrm{BB}$, whereas a more clustered distribution of mating types seemed to be present in UL (Fig. 1). This was confirmed by aggregation analyses, which showed weak aggregation indexes in BB $(0.30$, not significant) and significant, high aggregation indices in UL (UL 2011/2013: 0.77, $p$ value $=0$; UL 2011: 0.93, $p$ value $=0$ and UL 2013: $0.75, p$ value $=0$; Table 1). Since this reflects clonal growth rather than clustering of different genets bearing the same mating type, we performed these analyses at the genet level using the clone-corrected dataset including several centred locations for large genets (Fig. S2). Here, we found no indication of mating-type aggregation in the BB site but still a significant aggregation value in UL 2011/2013 $(0.55 ; p$ value $=0.03)$ and $\mathrm{UL} 2013(0.57 ; p$ value $=$ 0.03). With this dataset, a MAT1-1:MAT1-2 ratio of 0.90 (not significant) was found in $\mathrm{BB}$, a ratio of 2 was found for UL 2011/2013 ( $p$ value $=0.03$ ), and a ratio of 5 was found for UL 2011 ( $p$ value $=0.03$ ). For UL 2013, the ratio MAT11:MAT1-2 was 1.75 and did not deviate significantly from a 1:1 mating-type ratio.

\section{MLGs analyses}

The 112 fruiting bodies of T. aestivum were successfully genotyped using the 14 SSR markers. All SSRs were polymorphic except one, the locus aest15 (Table S3a). SSR markers presented 1 to 4 alleles (Table S3a). One and seven SSRs were monomorphic for $\mathrm{BB}$ and $\mathrm{UL}$, respectively (Table S3b). By combining the mating-type and SSR profiles, a total of 41 MLGs were identified, 26 for BB and 15 for UL (Table 1). When plotting the genotypic diversity and the number of 


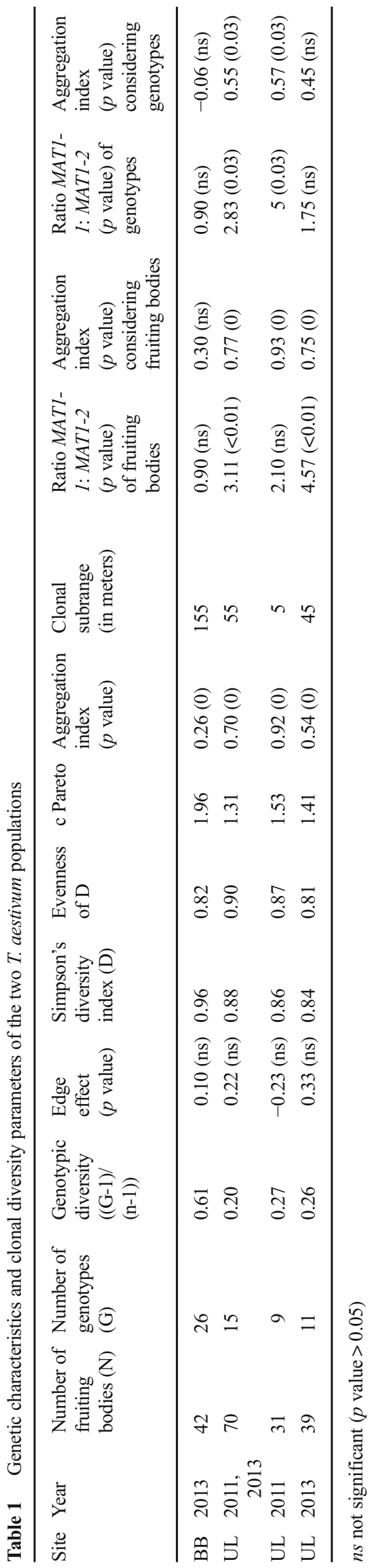

MLG against the number of loci, no plateau was observed; there was a genotypic diversity of 0.949 for 15 loci (i.e. with mating gene) and increasing numbers of MLGs (Fig. S5). Since no plateau was reached, it cannot be excluded that additional markers would increase the genotypic diversity.

No MLG was shared between the two sites (Table S4). In BB, seven MLG (27\%) had several ramets (i.e. several fruiting bodies), and a significant $P_{\text {sex }}$ value indicated that they belonged to the same genet (Table S4). In the UL site, nine MLG (60\%) had several ramets and, with the exception of MLG 21 and MLG 35, all MLG can be considered as genets (Table S4). For MLG21 and MLG35, the two fruiting bodies were each treated as different MLGs (e.g., 21a, 21b). Two thirds of MLGs found in UL were present in only one of the two seasons, whereas five MLGs were found in both 2011 and 2013 (Table S4). Although collected at the same time, many fruiting bodies formed by the same MLG showed different weights and maturity stages from unripe to fully ripe ones in both sites (e.g. MLG 17, MLG 36; Table S2).

\section{Clonal diversity and spatial genetic structure}

In $\mathrm{BB}$, the genotypic diversity $(R)$ was high $(0.61)$. Lower $R$ values were obtained for UL in each year and in 2011 and 2013 combined (0.20-0.27; Table 1). No significant edge effects (Ee) were detected in any analyses, indicating that there was no sampling bias and that the sampling scheme was adequate to estimate the genotypic diversity. High values were found for both the Simpson's diversity index (0.96 in BB and 0.84 to 0.88 in UL) and the evenness index ( 0.82 in BB and from 0.81 to 0.90 in UL) (Table 1). The $c$ Pareto values ranged from 1.31 to 1.96 (Table 1). These three indices were quite similar for both truffle sites and indicate that the populations show a high diversity, with relatively equal abundances of different MLGs.

The estimated aggregation index (Ac) was 0.26 ( $p$ value $<$ $0.001)$ for $\mathrm{BB}$ and 0.70 ( $p$ value $<0.001)$ for UL (2011 and 2013 combined) (Table 1). This indicates that on BB, only $26 \%$ of the nearest neighbours share the same MLG, whereas the majority $(70 \%)$ of the nearest neighbours on UL share the same MLG. The largest genet size was found in BB, stretching $155 \mathrm{~m}$, whereas in UL the maximum sizes were 5, 45 and $55 \mathrm{~m}$ for 2011, 2013 and 2011/2013 combined, respectively (Table 1, Fig. 1). However, genet sizes were generally small in both sites (Table S4). In BB, $70 \%$ of the genets were only found once, whereas a maximum of $40 \%$ of the genets were unique in UL for single years and for 2011 and 2013 combined (Table S4). Clonal parameters seem to be unbiased by the different sampling areas except for the maximum genet size observed (Fig. S2, Table S5).

Spatial autocorrelation of the kinship coefficient $\left(F_{\mathrm{ij}}\right)$ revealed a significant positive correlation for distances up to $4 \mathrm{~m}$ in BB and up to $6.5 \mathrm{~m}$ in UL when all sampled fruiting bodies were considered (ramet level; Fig. 2). Sp, which 
a

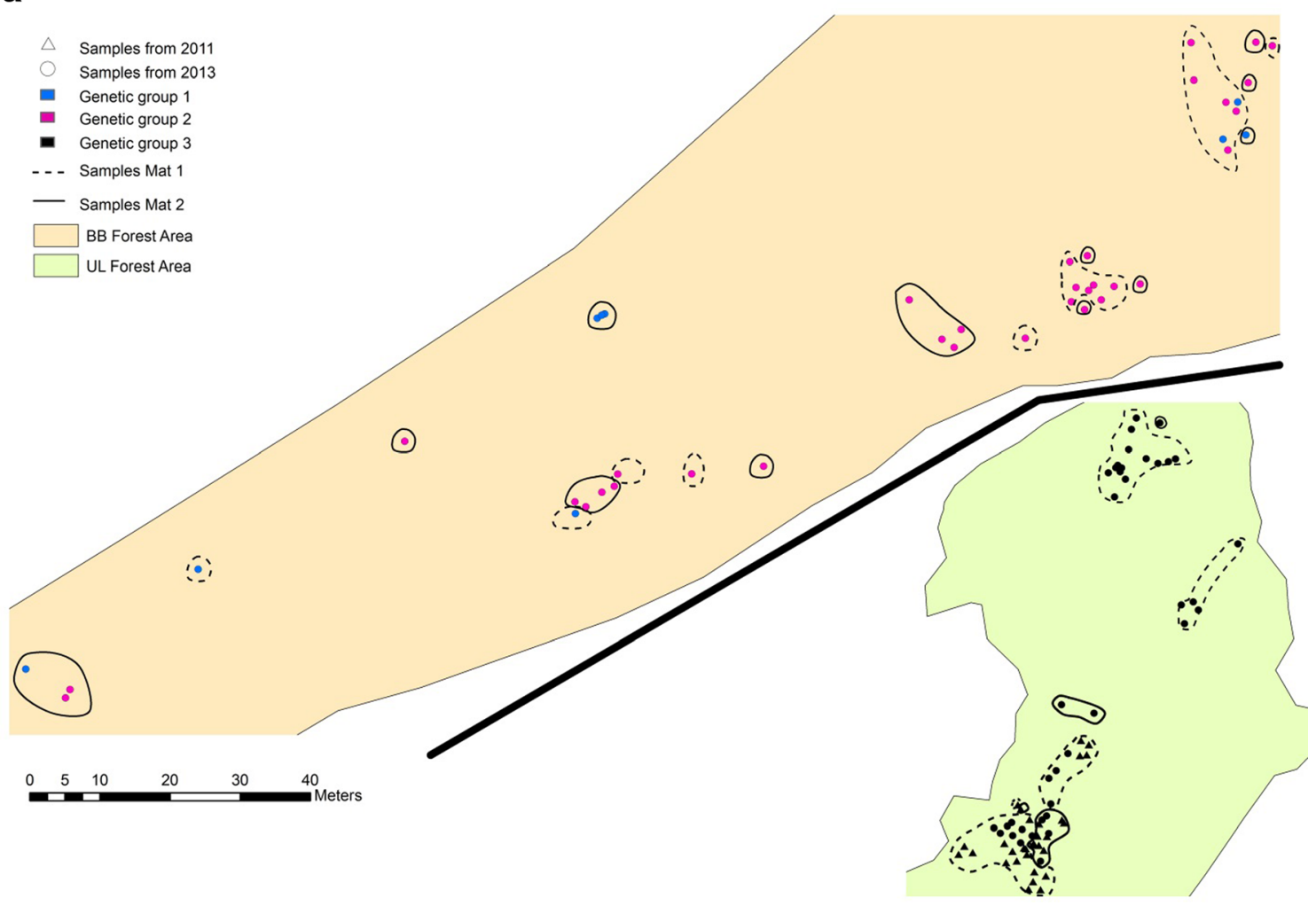

b

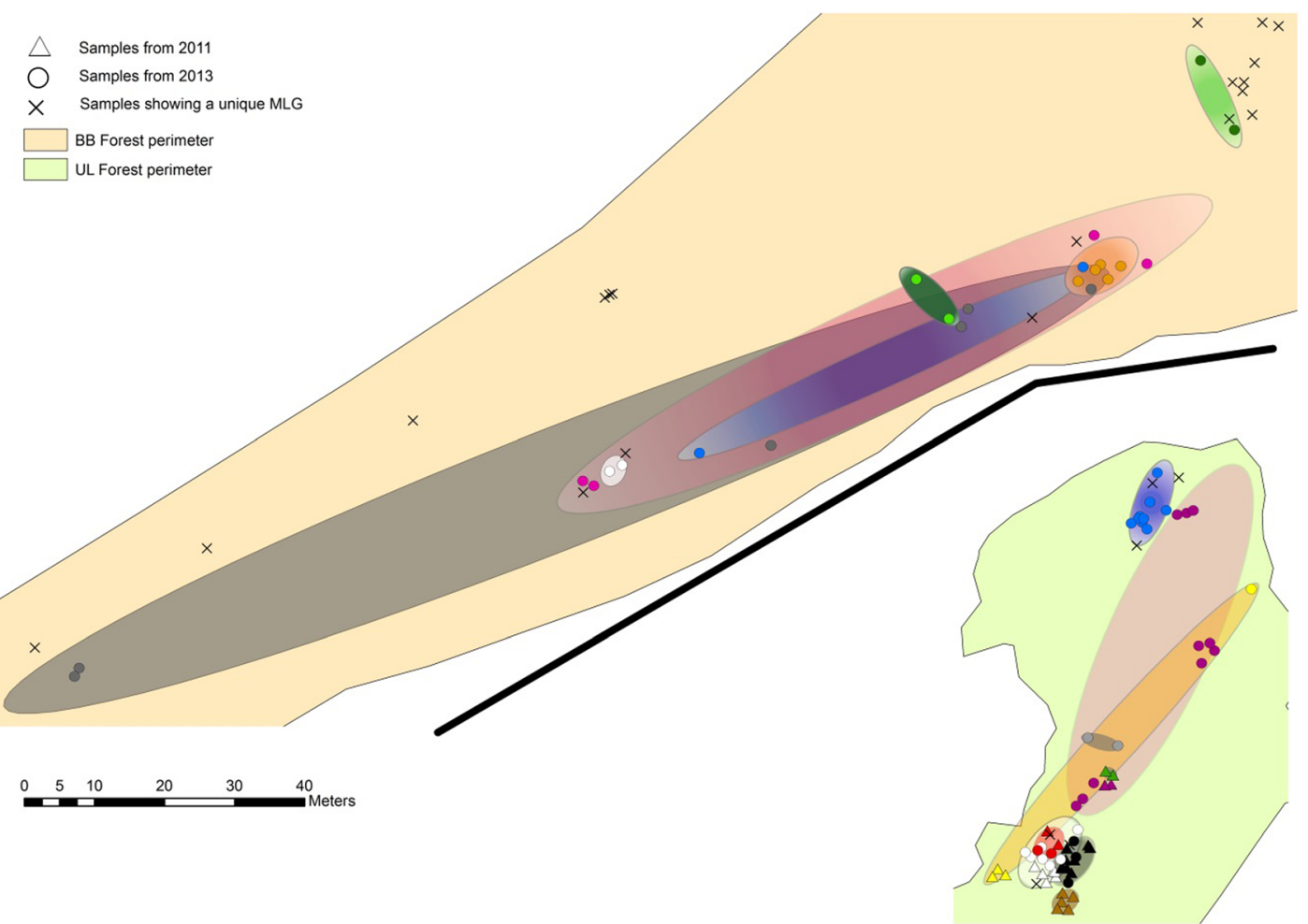

Fig. 1 Schematic representation of BB and UL sites. Mating type and genetic group memberships of each sample are given in (a) and genotype mapping is given in (b). In a, mating-type strains (Mat 1 and Mat 2) are indicated in dashed (Mat 1) or solid (Mat 2) lines. The three different genetic groups are indicated in colour $(1=$ blue, $2=$ pink and 3 =black $)$.
In b, crosses represent samples showing a unique multi-loci genotype, whereas shared multi-loci genotypes are represented by triangles (samples from 2011) or dots (samples from 2013). Sizes of genets are represented by the sizes of colored ovals 

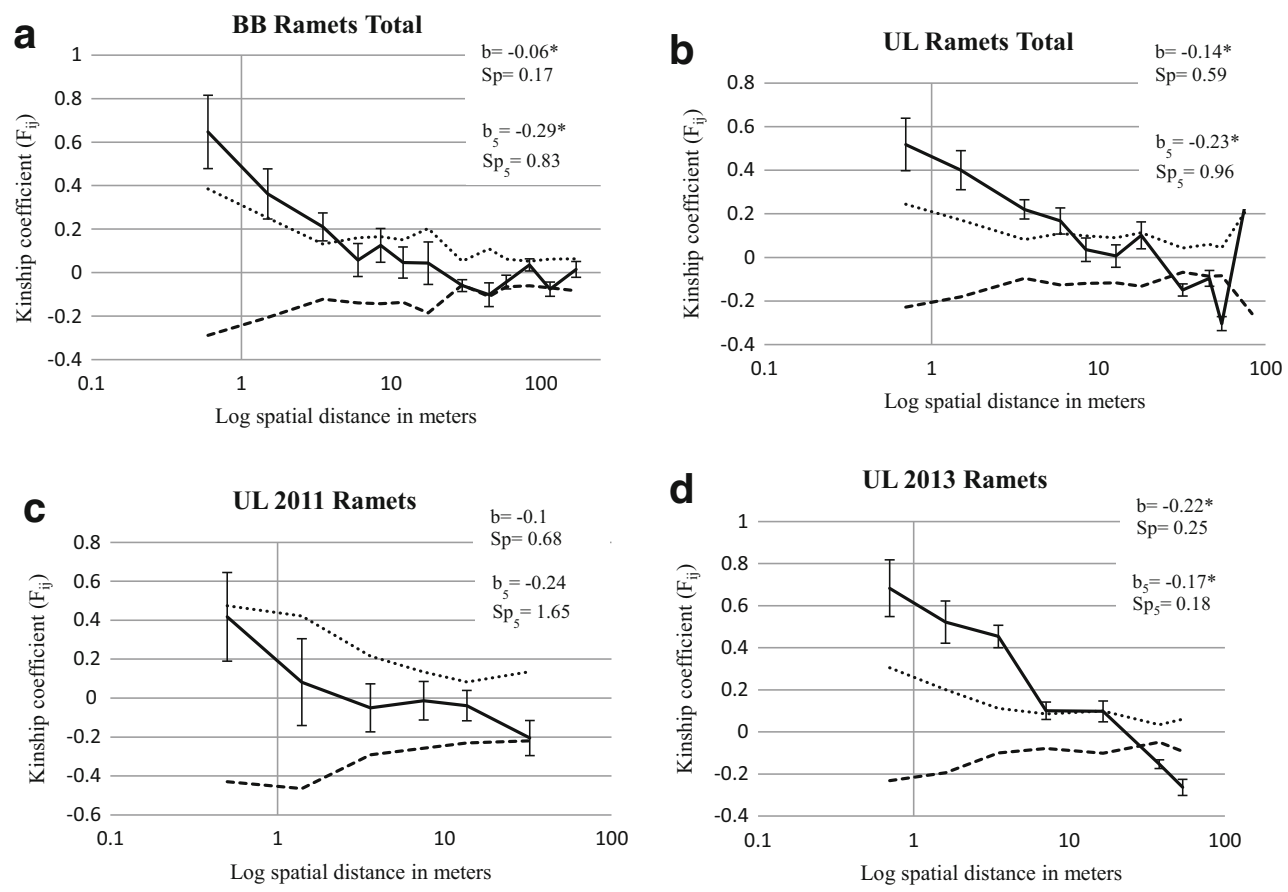

Fig. 2 Spatial autocorrelogram of the kinship coefficient $\left(F_{i j}\right)$ as a function of the log of the spatial distance. Panels (a), (b), (c) and (d) represent the autocorrelograms for which all ramets were used for BB and UL, UL in 2011 and UL in 2013, respectively. The dashed lines correspond to the $95 \%$ confidence interval for the null hypothesis of complete spatial randomness of genotypes, constructed by 10,000 permutations of genotypes across individual positions. The slope of the

regression of kinship with $\log ($ dist $)$ is indicated as $b$ for each correlogram. The statistic $(\mathrm{Sp})$, defined as the ratio $-b /\left(1-F_{1}\right)$, where $b$ is the regression slope of the autocorrelogram and $F_{1}$ is the mean $F_{\mathrm{ij}}$ between the individuals belonging to the first distance class that includes all pairs of neighbours (Vekemans \& Hardy, 2004), is indicated for each autocorrelogram. An asterisk indicates a b-log with a $p$ value $<0.05$

reflects the rate of decrease in pairwise kinship over distance, was higher in UL for single and combined years $(0.59,0.68$ and 0.25 for UL 2011/2013, UL2011 and UL2013, respectively) than in $\mathrm{BB}(0.17)$, indicating a stronger spatial genetic structure (SGS) in the first site when ramets are considered (Fig. 2). These values increased strongly if autocorrelation was analysed within $5 \mathrm{~m}$ only (Fig. 2). At the genet level, we still found a positive spatial autocorrelation of kinship in both sites, although this relationship was less clear, and similar slopes and $\mathrm{Sp}$ values were found for both sites when all distance ranges were considered. However, within the first $5 \mathrm{~m}$, a much more pronounced SGS was observed for BB than for UL, with the highest significant Sp value (1.43) of all datasets (Fig. S6).

STRUCTURE analysis revealed three well-differentiated genetic groups, two in BB (genetic group 1 and genetic group 2) and one in UL (genetic group 3; Fig. 1). The fixation indices $\left(F_{\mathrm{st}}\right)$ between all genetic groups were high $(0.49-0.65$; Table 2), indicating a clear differentiation between genetic groups even when present within the same site. The genetic relatedness of samples within a genetic group was high, while lower and negative kinship values were observed between genetic groups (Table 2). The two genetic groups present in the BB site seemed to be spatially intermingled because no significant aggregation was found according to the genetic

group membership (0.39; not significant). Almost twice as many genets were found in genetic group 2 compared to genetic group 1, the first harbouring larger genets and the last only showing unique genets (Table S4). The average maturity of fruiting bodies from these two genetic groups did not differ (Table S2). We added the dataset from this particular study into the European dataset published in 2015 (Molinier et al. 2015b) and reran the STRUCTURE analysis. It revealed that all genotypes of the dataset presented here belong to the European genetic group 4.

Table 2 Matrix of genetic differentiation between pairs of genetic clusters. Genetic distance $\left(F_{\mathrm{st}}\right)$ values are indicated in the lower half of the matrix. Kinship coefficients $\left(F_{\mathrm{ij}}\right)$ between pairs of genetic groups and within genetic groups $\left(G_{\mathrm{ij}}\right)$ are indicated in the upper half of the matrix and in the diagonal line (in italics), respectively

\begin{tabular}{llll}
\hline ALL LOCI & Genetic group 1 & Genetic group 2 & Genetic group 3 \\
\hline Genetic group 1 & 0.47 & -0.15 & -0.08 \\
Genetic group 2 & 0.52 & 0.50 & -0.38 \\
Genetic group 2 & 0.49 & 0.65 & 0.56 \\
\hline
\end{tabular}




\section{Discussion}

\section{Sex and mating-type distribution of T. aestivum}

Taking advantage of the genomic resources recently generated (Payen et al., 2014), we confirm in the present study that T. aestivum, like many other Tuber spp., has a dominant haploid life cycle and a heterothallic sexual reproduction mode requiring two compatible mating-type strains. Similar to studies on T. melanosporum (Murat et al. 2013; Rubini et al. 2011a), there is some indication of maternal mating-type aggregation in our study site UL but not in BB. To be able to compare mating-type aggregation indices obtained in the current study with T. melanosporum data on fruiting bodies in the plantation of Rollainville (Murat et al. 2013), we calculated these indices for data presented by Murat et al. (2013) and found that aggregation was considerably higher in the T. melanosporum plantation ( 0.83 and 0.84 at the ramet and the genet level, respectively). We also observed significant aggregation of mating types in both sites when all fruiting bodies (ramets) were considered, and in the UL site when only genets were considered. However, the first analyses based on ramets reflect clonal growth rather than mating-type clustering, whereas the second analysis might be biased in the UL site because MAT1-1 genets were much more abundant than those bearing MAT1-2. Therefore, more studies are needed to learn whether or not mating-type clustering occurs in T. aestivum. Our data indicates that such a tendency is less pronounced in $T$. aestivum than in T. melanosporum, which suggests that not all Tuber species behave in the same way. However, if aggregation is present, it might be explained by the vegetative incompatibility system, which is responsible for rejection of non-compatible strains during vegetative growth (Leslie and Zeller, 1996; Glass et al. 2000). The mating-type locus is one of the loci controlling vegetative incompatibility (Glass et al. 2000). These mechanisms, which block the formation of heterokaryotic mycelia, also exist in Tuber spp. (Sbrana et al. 2007). Selosse et al. (2013) proposed that one possible explanation from an evolutionary point of view justifying the link between mating-type genes and vegetative incompatibility is that the resulting spatial segregation decreases the probability that compatible cells meet. A lower probability of mating is beneficial under the assumption that sex is costly (Selosse et al. 2013).

Interestingly, unequal abundances of mating types with significantly more MAT1-1 samples were previously observed on tree roots in Australian T. melanosporum populations (Linde and Selmes 2012). The authors hypothesized that, if not due simply to insufficient sample sizes, such a skew could arise from competition on the host trees, and the dominant mating type could be linked to a gene under selection, providing a competitive advantage. However such a bias was not found in some other studies of T. melanosporum (Murat et al. 2013; Rubini et al. 2011a); clearly, this possibility needs to be investigated further, both in the field with large sample sizes of fruiting bodies and mycorrhizal root tips and in genomic studies.

\section{Propagation strategy of $T$. aestivum}

The propagation of ECM fungi is intimately related to the host-plant roots since they are obligatory symbionts (Smith and Read 2008). To maintain and extend a population, fungi need to colonize the root system either by mycelial spread from existing individuals or via the recruitment of new genets through spore germination. The trade-off between asexual growth and sexual reproduction can be species specific ( $\mathrm{r}-$ or $\mathrm{K}$-strategy) or correlated with some extrinsic environmental factors, such as disturbance or forest age (Douhan et al. 2011). While it is clear that T. aestivum is an ECM fungus adapted to a wide range of host trees and climatic conditions (Molinier et al. 2016; Stobbe et al. 2013a), not much is known about its propagation strategy and its reaction to disturbances within a population. The present results show that $T$. aestivum forms many rather small genets with mostly only one fruiting body per genet and with a high genet turnover, suggesting a ruderal colonization strategy (r-strategy). This finding was more obvious on site BB than on UL. R-strategists spread and colonize by sexual spores rather than by vegetative growth (Dahlberg and Stenlid 1994; Deacon 1992). The same pattern was described for T. melanosporum (Murat et al. 2013) and in naturally colonized $T$. aestivum plantations (Molinier et al. 2015a). The high genetic diversity found here is in agreement with previous results from small-scale (Molinier et al. 2015a) and large-scale studies of T. aestivum (Gandeboeuf et al. 1997; Mello et al. 2002; Molinier et al. 2013a; Molinier et al. 2015b; Pacioni and Pomponi 1991; Paolocci et al. 2004; Weden et al. 2004). This high diversity is probably linked to the ubiquitous presence of $T$. aestivum throughout Europe and its adaptation to different climate and site conditions.

Although mostly small genets were observed in our study, some individuals spanned more than $100 \mathrm{~m}$, which is significantly larger than the observed maximum size of $4.7 \mathrm{~m}$ for T. melanosporum in artificial plantations (Murat et al. 2013). Our results are in agreement with the maximum size of $92 \mathrm{~m}$ recently published in a study on naturally colonized T. aestivum sites (Molinier et al. 2015a). If the observed genet sizes originated from mycelial growth, $T$. aestivum would be one of the ECM fungal species forming the largest genets (Douhan et al 2011). Maximum genet sizes of $110 \mathrm{~m}$ have been observed for the basidiomycete Xerocomus chrysenteron (Fiore-Donno and Martin 2001), followed by the Tricholoma scalpturatum complex (Carriconde et al. 2008) and Suillus pungens (Bonello et al. 1998), both with a maximum size of $40 \mathrm{~m}$. Besides the species-specific colonization strategy and growth capacity, environmental parameters such as forest age 
and degree of disturbance can influence vegetative mycelial growth (review in Douhan et al. 2011). The large genet sizes observed in our study can be explained by the fact that our study took place in natural, only sporadically managed forests including trees more than 100 years old. However, T. aestivum has an in vitro growth of $2-4 \mathrm{~mm}$ per week, which is slow compared to other mycorrhizal fungi (Iotti et al. 2002 and our own unpublished observations). Gryndler et al. (2015) observed similar growth rates in a field survey ( $3 \mathrm{~mm}$ per week). To reach the size observed in our study of $155 \mathrm{~m}$ would therefore take almost 1000 years. Although unlikely, this would be possible if our site was continuously forested for this long period. Unfortunately, no long-term data about forest history are available. However, such a large genet size might alternatively have emerged from mycelial fragments sticking to and thus being distributed by animals or humans. In addition, the genets could spread via mitospores, the formation of which has been shown for other Tuber species (Healy et al 2013).

Our kinship analyses indicate that $T$. aestivum shows significant spatial genetic structure (SGS) in natural sites within the first $5 \mathrm{~m}$. Such a high SGS is typical for species that disseminate spores by animals rather than wind (Vekemans and Hardy 2004) and our observations are consistent with those for T. melanosporum (Murat et al 2013). This finding indicates that offspring preferentially stays close to the parents, maybe through the decay of fruiting bodies not harvested by animals. Such a pattern might also arise by the active vegetative incompatibility system mentioned above, in which kin and non-kin individuals are differentiated and the local distribution of genets is shaped by the sharing of space among kin and the protection from resource access by non-kin.

Even if T. aestivum appears to have the same life strategy as other truffles, the season and the timing of sexual encounters and fruiting body development is still unclear. Tuber magnatum and T. melanosporum show a relatively short season in which fruiting bodies can be found (from September to the end of December and from December to March, respectively). In contrast, fully mature $T$. aestivum fruiting bodies can be harvested over a much longer season (Stobbe et al. 2013a). In the present study, we found no clear correlation between maturity and weight of fruiting bodies from a single harvest. Further, the same maternal mycelium was found in fruiting bodies of all maturity stages. Given the fact that a period of 5 months has been suggested for completion of maturation for T. melanosporum (Pacioni et al. 2014), we can assume that the same maternal tissue of T. aestivum can fructify more than once per year. Therefore, the life cycle of T. aestivum is likely to have several short reproductive periods and can be more complex than that of other studied truffle species.

In one of the present study sites, we found two welldifferentiated genetic groups, indicating limited gene flow between them, although they were spatially not clearly separated. Another type of barrier might exist and explain their sympatric presence. Interestingly, the two genetic groups seem to differ in their colonization strategy: whereas one consists solely of unique and small genets, the other one harbours individuals that had formed several fruiting bodies and which had spread vegetatively to form larger genets. These different strategies might explain the high genetic differentiation between the two genetic groups, and a genetic determinant might exist that enables competitive vegetative spread.

\section{Differences in the genetic structure of the T. aestivum populations within the two natural sites}

Although the sites BB and UL are located only $3 \mathrm{~km}$ apart and show similar physico-chemical soil characteristics, no gene flow seems to occur. Such a high genetic differentiation has already been shown for the hypogeous species Rhizopogon occidentalis, where a high $F_{\text {st }}$ value $(0.26)$ was found between populations separated by $8.5 \mathrm{~km}$ (Grubisha et al. 2007). The authors attributed this finding to geographic dispersal barriers, a limited number of mammal dispersers in the area, and a large Rhizopogon spore bank. In our study, the site UL is isolated by agricultural fields, and thus geographic barriers, at least for vegetative dispersion, could explain the limited gene flow. In addition, small mammals like rodents are efficient short-distance dispersers (Urban 2016), with dispersal limits below $50 \mathrm{~m}$ (Frank et al. 2009), which might not be far enough to cross these agricultural fields. Larger mammals such as boars can also be effective vectors of T. aestivum (Piattoni 2012; Piattoni et al. 2014). However, even if present in this area, such animals apparently do not lead to a genetic exchange of $T$. aestivum between the two studied sites, and further studies are required to estimate how efficient they are as truffle dispersers.

Besides the lack of gene flow, we also observed some differences in genetic diversity and spatial genetic structure between the two sites. On site UL, we observed fewer genetic individuals belonging to one genetic group, which tend to show expanded genet sizes, than on BB. In addition, the genotypic diversity was higher and genets tended to have more restricted sizes, stronger spatial genetic structuring, and clearer grouping into two well-differentiated genetic groups on site UL compared to site BB. On BB, we observed a genetic pattern very similar to that found for T. melanosporum (Murat et al. 2013), except for maternal mating-type genotype aggregation. The most obvious environmental difference between the two sites is the fact that agricultural fields surround UL, whereas BB is a large and interconnected forest. Therefore, $\mathrm{UL}$ is an isolated site and has a limited effective population size, whereas in BB, spore dispersion by animals from larger areas is more probable and may allow incoming spores to establish small genets. A more intense genetic turnover in the connected forest compared to in the isolated one may have led to the observed higher genotypic diversity on site BB. 
Interestingly, mycelial growth seems to be more favoured on site UL, which might be a consequence of fewer disturbances in an unmanaged forest with limited human activity. Over the longer term, the composition of tree species (potential T. aestivum hosts) and of shrubs and herbs in the understory layer could influence the genetic structure of $T$. aestivum if genets have different host preferences, as shown previously for arbuscular mycorrhizal fungi (Croll et al. 2008).

To conclude, T. aestivum growing in natural forest stands is genetically highly diverse, mainly forms small genets (although very large genets do occur occasionally) and presents a high spatial genetic structure over only a few meters. T. aestivum can have different colonization strategies depending on site conditions. This new knowledge on the life history traits of this truffle species is highly important for maintaining sustainable long-term truffle production, both in artificial plantations and in natural habitats.

Acknowledgments This project was supported by the COST action Project FP1203, the Swiss State Secretariat for Education Research and Innovation (SERI), the WSL-internal "DITREC" project, as well as the "Ernst Göhner Stiftung"(Grant 2012-1961/3). Virginie Molinier was paid by SERI. The UMR1136 is supported by a grant overseen by the French National Research Agency (ANR) as part of the "Investissements d'Avenir" program (ANR-11-LABX-0002-01, Lab of Excellence ARBRE). The authors thank Genoscope for financing the Tuber aestivum genome sequencing in the TUBEREVOL project. Daniel Nievergelt and Christian Ginzler supported fieldwork, and Francesco Paolocci contributed to discussion. The authors thank Melissa Dawes for providing English language suggestions. The authors thank the three anonymous reviewers for their helpful comments.

\section{References}

Agapow PM, Burt A (2001) Indices of multilocus linkage disequilibrium. Mol Ecol Notes 1(1-2):101-102. doi:10.1046/j.1471-8278.2000.00014.x

Arnaud-Haond S, Belkhir K (2007) genclone: a computer program to analyse genotypic data, test for clonality and describe spatial clonal organization. Mol Ecol Notes 7(1):15-17. doi:10.1111/j.1471-8286.2006.01522.x

Arnaud-Haond S, Duarte CM, Alberto F, Serrão EA (2007) Standardizing methods to address clonality in population studies. Mol Ecol 16(24):5115-5139. doi:10.1111/j.1365-294X.2007.03535.x

Belfiori B, Riccioni C, Paolocci F, Rubini A (2013) Mating type locus of Chinese black truffles reveals heterothallism and the presence of cryptic species within the $T$. Indicum species complex. PLoS ONE 8(12):e82353. doi:10.1371/journal.pone. 0082353

Benucci GMN, Raggi L, Albertini E, Grebenc T, Bencivenga M, Falcinelli M, Di Massimo G (2011) Ectomycorrhizal communities in a productive Tuber aestivum vittad. Orchard: composition, host influence and species replacement. FEMS Microbiol Ecol 76:170-184. doi:10.1111/j.1574-6941.2010.01039.x

Benucci G, Bonito G, Falini L, Bencivenga M (2012) Mycorrhization of pecan trees (Carya illinoinensis) with commercial truffle species: Tuber aestivum vittad. And Tuber borchii vittad. Mycorrhiza 22(5):383-392. doi:10.1007/s00572-011-0413-z

Billiard S, LÓPez-Villavicencio M, Hood ME, Giraud T (2012) Sex, outcrossing and mating types: unsolved questions in fungi and beyond. J Evolution Biol 25:1020-1038. doi:10.1111 /j.1420-9101.2012.02495.x
Bonello P, Bruns TD, Gardes M (1998) Genetic structure of a natural population of the ectomycorrhizal fungus Suillus pungens. New Phytol 138:533-542. doi:10.1046/j.1469-8137.1998.00122.x

Bonito GM, Gryganskyi AP, Trappe JM, Vilgalys R (2010) A global meta-analysis of Tuber ITS rDNA sequences: species diversity, host associations and long-distance dispersal. Mol Ecol 19:4994-5008. doi:10.1111/j.1365-294X.2010.04855.x

Bonito G, Smith ME, Nowak M, Healy RA, Guevara G, Cázares E, Kinoshita A, Nouhra ER, Domínguez LS, Tedersoo L, Murat C, Wang Y, Moreno BA, Pfister DH, Nara K, Zambonelli A, Trappe JM, Vilgalys R (2013) Historical biogeography and diversification of truffles in the Tuberaceae and their newly identified Southern hemisphere sister lineage. PLoS ONE 8(1):e52765. doi:10.1371/journal.pone.0052765

Carriconde F, Gryta H, Jargeat P, Mouhamadou B, Gardes M (2008) High sexual reproduction and limited contemporary dispersal in the ectomycorrhizal fungus Tricholoma scalpturatum: new insights from population genetics and spatial autocorrelation analysis. Mol Ecol 17:4433-4445. doi:10.1111/j.1365-294X.2008.03924.x

Ceruti A, Fontana A, Nosenzo C (2003) Le specie europee del genere Tuber, una revisione storica. Regione Piemonte, Museo regionale di Scienze Naturali de Torino, Torino, p 557, monografie XXXVII

Chevalier G, Grente J, Pollacsek A (1973) Obtention de mycorhizes de différents Tuber par synthèse à partir de spores en conditions gnotoxéniques et à partir de cultures pures de mycélium en conditions axéniques et gnotoxéniques. Ann Phytopathologie 5:107-108

Croll D, Wille L, Gamper HA, Mathimaran N, Lammers PJ, Corradi N, Sanders IR (2008) Genetic diversity and host plant preferences revealed by simple sequence repeat and mitochondrial markers in a population of the arbuscular mycorrhizal fungus Glomus intraradices. New Phytol 178:672-687. doi:10.1111/j.1469-8137.2008.02381.x

Cullere L, Ferreira V, Chevret B, Venturini ME, Sanchez-Gimeno AC, Blanco D (2010) Characterisation of aroma active compounds in black truffles (Tuber melanosporum) and summer truffles (Tuber aestivum) by gas chromatography-olfactometry. Food Chem 122:300-306. doi:10.1016/j.foodchem.2010.02.024

Dahlberg A, Stenlid J (1994) Size, distribution and biomass of genets in populations of Suillus bovinus (L.: Fr.) Roussel revealed by somatic incompatibility. New Phytol 128:225-234. doi:10.2307/2558318

Deacon JW (1992) Interactions of ectomycorrhizal fungi mycorrhizal functioning: an integrative plant-fungal process

Diaz P, Ibanez E, Reglero G, Senorans FJ (2009) Optimization of summer truffle aroma analysis by SPME: Comparison of extraction with different polarity fibres. Lwt-Food Sci Technol 42(7):1253-1259

Douhan GW, Vincenot L, Gryta H, Selosse MA (2011) Population genetics of ectomycorrhizal fungi: from current knowledge to emerging directions. Fungal Biol 115:569-597. doi:10.1016/j. funbio.2011.03.005

Earl D, vonHoldt B (2012) STRUCTURE HARVESTER: a website and program for visualizing STRUCTURE output and implementing the Evanno method. Conserv Genet Resour 4(2):359-361. doi:10.1007 /s12686-011-9548-7

Evanno G, Regnaut S, Goudet J (2005) Detecting the number of clusters of individuals using the software STRUCTURE: a simulation study. Mol Ecol 14:2611-2620. doi:10.1111/j.1365-294X.2005.02553.x

Fiore-Donno A-M, Martin F (2001) Populations of ectomycorrhizal Laccaria amethystina and Xerocomus spp. show contrasting colonization patterns in a mixed forest. New Phytol 152:533-542. doi:10.1046/j.0028-646X.2001.00271.x

Frank JL, Anglin S, Carrington EM, Taylor DS, Viratos B, Southworth D (2009) Rodent dispersal of fungal spores promotes seedling establishment away from mycorrhizal networks on Quercus garryana. Botany 87:821-829. doi:10.1139/B09-044

Gandeboeuf D, Dupre C, RoeckelDrevet P, Nicolas P, Chevalier G (1997) Grouping and identification of (Tuber) species using RAPD markers. Can J Bot-Rev Can Botanique 75(1):36-45 
Glass NL, Jacobson DJ, Shiu PK (2000) The genetics of hyphal fusion and vegetative incompatibility in filamentous ascomycete fungi. Annu Rev Genet 34:165-186

Grubisha LC, Bergemann SE, Bruns TD (2007) Host islands within the California Northern Channel Islands create fine-scale genetic structure in two sympatric species of the symbiotic ectomycorrhizal fungus Rhizopogon. Mol Ecol 16:1811-1822. doi:10.1111 j.1365-294X.2007.03264.x

Gryndler M, Hrselova H, Soukupova L, Streiblova E, Valda S, Borovicka J, Gryndlerova H, Gazo J, Miko M (2011) Detection of summer truffle (Tuber aestivum Vittad.) in ectomycorrhizae and in soil using specific primers. Fems Microbiol Lett 318:84-91. doi:10.1111/j.1574-6968.2011.02243.x

Gryndler M, Beskid O, Hršelová H, Bukovská P, Hujslová M, Gryndlerová H, Konvalinková T, Schnepf A, Sochorová L, Jansa J (2015) Mutabilis in mutabili: Spatiotemporal dynamics of a truffle colony in soil. Soil Biol Biochem 90:62-70. doi:10.1016/j.soilbio.2015.07.025

Hardy OJ (2003) Estimation of pairwise relatedness between individuals and characterization of isolation-by-distance processes using dominant genetic markers. Mol Ecol 12:1577-1588. doi:10.1046/j.1365294X.2003.01835.X

Hardy OJ, Vekemans X (2002) SPAGEDi: a versatile computer program to analyse spatial genetic structure at the individual or population levels. Mol Ecol Notes 2:618-620. doi:10.1046 j.1471-8286.2002.00305.x

Healy RA et al (2013) High diversity and widespread occurrence of mitotic spore mats in ectomycorrhizal pezizales. Mol Ecol 22:1717-1732

Iotti M, Amicucci A, Stocchi V, Zambonelli A (2002) Morphological and molecular characterization of mycelia of some Tuber species in pure culture. New Phytol 155:499-505. doi:10.1046 j.1469-8137.2002.00486.x

Jeandroz S, Murat C, Wang YJ, Bonfante P, Le Tacon F (2008) Molecular phylogeny and historical biogeography of the genus Tuber, the 'true truffles'. J Biogeography 35:815-829. doi:10.1111 /j.1365-2699.2007.01851.x

Landolt E (2010) Flora indicativa: ecological indicator values and biological attributes of the flora of Switzerland and the Alps, 2nd edn. Haupt, Bern

Le Tacon F, Rubini A, Murat C, Riccioni C, Robin C, Belfiori B, Zeller B, De la Varga H, Akroume E, Deveau A, Martin F, Paolocci F (2015) Certainties and uncertainties about the life cycle of the Périgord black truffle (Tuber melanosporum Vittad.). Ann Forest Sci:1-13. doi:10.1007/s13595-015-0461-1

Leslie JF, Zeller KA (1996) Heterokaryon incompatibility in fungi: more than just another way to die. J Genet 75:415-424

Linde CC, Selmes H (2012) Genetic diversity and mating type distribution of tuber melanosporum and their significance to truffle cultivation in artificially planted truffiéres in Australia. Appl Environm Microbiol 78:6534-6539. doi:10.1128/aem.01558-12

Loiselle BA, Sork VL, Nason J, Graham C (1995) Spatial geneticstructure of a tropical understory shrub, Psychotria officinalis (Rubiaceae). Am J Bot 82:1420-1425. doi:10.2307/2445869

Martin F, Kohler A, Murat C, Balestrini R, Coutinho PM, Jaillon O, Montanini B, Morin E, Noel B, Percudani R, Porcel B, Rubini A, Amicucci A, Amselem J, Anthouard V, Arcioni S, Artiguenave F, Aury JM, Ballario P, Bolchi A, Brenna A, Brun A, Buee M, Cantarel B, Chevalier G, Couloux A, Da Silva C, Denoeud F, Duplessis S, Ghignone S, Hilselberger B, Iotti M, Marcais B, Mello A, Miranda M, Pacioni G, Quesneville H, Riccioni C, Ruotolo R, Splivallo R, Stocchi V, Tisserant E, Viscomi AR, Zambonelli A, Zampieri E, Henrissat B, Lebrun MH, Paolocci F, Bonfante P, Ottonello S, Wincker P (2010) Perigord black truffle genome uncovers evolutionary origins and mechanisms of symbiosis. Nature 464(7291):1033-1038. doi:10.1038/nature08867
Mello A, Cantisani A, Vizzini A, Bonfante P (2002) Genetic variability of Tuber uncinatum and its relatedness to other black truffles. Environ Microbiol 4(10):584-594

Molinier V, Murat C, Morin E, Gollotte A, Wipf D, Martin F (2013a) First Identification of polymorphic microsatellite markers in the burgundy truffle, Tuber aestivum (Tuberaceae). Appl Plant Sci 1 (2): 1200220. doi:10.3732/apps. 1200220

Molinier V, van Tuinen D, Chevalier G, Gollotte A, Wipf D, Redecker D (2013b) A multigene phylogeny demonstrates that Tuber aestivum and Tuber uncinatum are conspecific. Organ Divers Evol 13:503-512

Molinier V, Murat C, Frochot H, Wipf D, Splivallo R (2015a) Fine-scale spatial genetic structure analysis of the black truffle Tuber aestivum and its link to aroma variability. Environ Microbiol doi:10.1111 /1462-2920.12910

Molinier V, Murat C, Peter M, Gollotte A, De la Varga H, Meier B, Egli S, Belfiori B, Paolocci F, Wipf D (2015b) SSR- based identification of genetic groups within European populations of Tuber aestivum Vittad Mycorrhiza doi: 10.1007/s00572-015-0649-0

Molinier V, Stobbe U, Peter M, Egli S (2016) The Burgundy truffle (Tuber aestivum syn. uncinatum) - a truffle species with a wide habitat range over Europe. In: Zambonelli A, Iotti M, Murat C (eds) True Truffles (Tuber spp.) of the World, vol 47. Soil Biology Springer

Murat C, Rubini A, Riccioni C, De la Varga H, Akroume E, Belfiori B, Guaragno M, Le Tacon F, Robin C, Halkett F, Martin F, Paolocci F (2013) Fine-scale spatial genetic structure of the black truffle (Tuber melanosporum) investigated with neutral microsatellites and functional mating type genes. New Phytol 199(1):176-187. doi:10.1111/nph.12264

Pacioni G, Pomponi G (1991) Genotypic patterns of some Italian populations of the Tuber aestivum-Tuber mesentericum complex. Mycotaxon 42:171-179

Pacioni G, Leonardi M, Di Carlo P, Ranalli D, Zinni A, De Laurentiis G (2014) Instrumental monitoring of the birth and development of truffles in a Tuber melanosporum orchard. Mycorrhiza 24(1):65-72. doi:10.1007/s00572-014-0561-z

Paolocci F, Rubini A, Riccioni C, Topini F, Arcioni S (2004) Tuber aestivum and Tuber uncinatum: two morphotypes or two species? Fems Microbiol Lett 235(1):109-115

Paolocci F, Rubini A, Riccioni C, Arcioni S (2006) Reevaluation of the life cycle of Tuber magnatum. Appl Environ Microbiol 72(4):2390-2393

Payen T, Murat C, Bonito G (2014) Truffle phylogenomics: new insights into truffle evolution and truffle life cycle. In: Martin F (ed) Advance in Botanical Research vol. 70, Elsevier, p 211-234

Piattoni F (2012) The role of wild boars in spore dispersal of hypogeous fungi. Acta Mycol 47(2):145-153

Piattoni F, Amicucci A, Iotti M, Ori F, Stocchi V, Zambonelli A (2014) Viability and morphology of Tuber aestivum spores after passage through the gut of Sus scrofa. Fung Ecol 9:52-60. doi:10.1016/j.funeco.2014.03.002

Pritchard JK, Stephens M, Donnelly P (2000) Inference of population structure using multilocus genotype data. Genetics 155(2):945-959

Riccioni C, Belfiori B, Rubini A, Passeri V, Arcioni S, Paolocci F (2008) Tuber melanosporum outcrosses: analysis of the genetic diversity within and among its natural populations under this new scenario. New Phytol 180(2):466-478

Rubini A, Paolocci F, Riccioni C, Vendramin GG, Arcioni S (2005) Genetic and phylogeographic structures of the symbiotic fungus Tuber magnatum. Appl Environ Microbiol 71(11):6584-6589. doi:10.1128/aem.71.11.6584-6589.2005

Rubini A, Belfiori B, Riccioni C, Arcioni S, Martin F, Paolocci F (2011a) Tuber melanosporum: mating type distribution in a natural plantation and dynamics of strains of different mating types on the roots of nursery-inoculated host plants. New Phytol 189 (3):723-735. doi:10.1111/j.1469-8137.2010.03493.x 
Rubini A, Belfiori B, Riccioni C, Tisserant E, Arcioni S, Martin F, Paolocci F (2011b) Isolation and characterization of MAT genes in the symbiotic ascomycete Tuber melanosporum. New Phytol 189 (3):710-722. doi:10.1111/j.1469-8137.2010.03492.x

Salerni E, Aguanno M, Leonardi P, Perini C (2014) Ectomycorrhizal communities above and below ground and truffle productivity in a Tuber aestivum orchard. Forest Syst 23 (2). doi:10.5424 /fs/2014232-04777

Sbrana C, Nuti MP, Giovannetti M (2007) Self-anastomosing ability and vegetative incompatibility of Tuber borchii isolate. Mycorrhiza 17:667-675

Selosse M-A, Taschen E, Giraud T (2013) Do black truffles avoid sexual harassment by linking mating type and vegetative incompatibility? New Phytol 199(1):10-13. doi:10.1111/nph.12329

Shamekh S, Grebenc T, Leisola M, Turunen O (2014) The cultivation of oak seedlings inoculated with Tuber aestivum Vittad. in the boreal region of Finland. Mycol Prog 13(2):373-380. doi:10.1007/s11557-013-0923-5

Smith SE, Read DJ (2008) Mycorrhizal symbiosis. Academic, London

Splivallo R, Valdez N, Kirchhoff N, Ona MC, Schmidt JP, Feussner I, Karlovsky P (2012) Intraspecific genotypic variability determines concentrations of key truffle volatiles. New Phytol 194(3):823-835. doi:10.1111/j.1469-8137.2012.04077.x

Stenberg P, Lundmark M, Saura A (2003) MLGsim: a program for detecting clones using a simulation approach. Mol Ecol Notes 3(2): 329-331. doi:10.1046/j.1471-8286.2003.00408.x

Stobbe U, Egli S, Tegel W, Peter M, Sproll L, Büntgen U (2013a) Potential and limitations of Burgundy truffle cultivation. Appl Microbiol Biotechnol 97 (12):5215-5224. doi:10.1007/s00253-013-4956-0
Stobbe U, Stobbe A, Sproll L, Tegel W, Peter M, Büntgen U, Egli S (2013b) New evidence for the symbiosis between Tuber aestivum and Picea abies. Mycorrhiza 23 (8):669-673. doi:10.1007/s00572-013-0508-9

Trappe J, Claridge A (2005) Hypogeous fungi: evolution of reproductive and dispersal strategies through interactions with animals and mycorrhizal plants. In: Dighton JWJ, Oudemans P (eds) The fungal community. Its organization and role in the ecosystem. CRC, Boca Raton, pp 599-611

Urban A (2016) Truffles and small mammals. In: Zambonelli A, Iotti M, Murat C (eds) True Truffles (Tuber spp.) of the World, vol 47. Soil Biology Springer

Vekemans X, Hardy OJ (2004) New insights from fine-scale spatial genetic structure analyses in plant populations. Mol Ecol 13(4): 921-935. doi:10.1046/j.1365-294X.2004.02076.x

Weden C, Danell E, Camacho FJ, Backlund A (2004) The population of the hypogeous fungus Tuber aestivum syn. T-uncinatum on the island of Gotland. Mycorrhiza 14(1):19-23. doi:10.1007 /s00572-003-0271-4

Weden C, Danell E, Tibell L (2005) Species recognition in the truffle genus Tuber-the synonyms Tuber aestivum and Tuber uncinatum. Environ Microbiol 7(10):1535-1546. doi:10.1111 /j.1462-2920.2005.00837.x

Zeppa S, Gioacchini AM, Guidi C, Guescini M, Pierleoni R, Zambonelli A, Stocchi V (2004) Determination of specific volatile organic compounds synthesised during Tuber borchii fruit body development by solid-phase microextraction and gas chromatography mass spectrometry. Rapid Commun Mass Spectrom 18(2):199-205. doi:10.1002 $/ \mathrm{rcm} .1313$ 